\title{
An Analytical Investigation of Thermal Buckling Behavior of Composite Plates Reinforced by Carbon Nano Particles
}

\author{
Muhannad Al-Waily ${ }^{1, a,}$, Mohsin Abdullah Al-Shammari ${ }^{2, b}$, and Muhsin J. Jweeg ${ }^{3, c}$ \\ 1 Department of Mechanical Engineering, Faculty of Engineering, University of Kufa, Najaf, Iraq \\ 2 Department of Mechanical Engineering, College of Engineering, University of Baghdad, Baghdad, Iraq \\ 3 College of Technical Engineering, Al-Farahidi University, Baghdad, Iraq

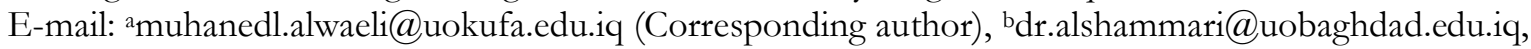 \\ cmuhsinjj@gmail.com
}

\begin{abstract}
The research used analytical and numerical methods to test thermal buckling activity for a composite plate structure with a range of Nano fractions. Experimental program with mechanical properties for the Nano composites were carried out and have been validated from previous work. In addition, both mechanical and thermal expansions were tested from previous work experimentally and used in numerical and analytical methods by the Nano composite. The general motion equation for thermal buckling load was derived and then, the results were compared with the numerical results. The analysis showed that the average outcome error was not greater $(2.49 \%)$. Ultimately, the results showed that the thermal effect results in a buckling of Nano particle strengthening $(1 \%)$ volume fraction for the adjusted structure of the plate leads to increase thermal buckling strength $(63,4 \%)$. This achievement modified a high thermal buckling strength with low percentage of Nano volume fraction compared to the previous work in this field.
\end{abstract}

Keywords: Composite materials, buckling plate, buckling structure, nano effect, thermal buckling.

ENGINEERING JOURNAL Volume 24 Issue 3

Received 25 September 2019

Accepted 22 February 2020

Published 31 May 2020

Online at https://engj.org/

DOI:10.4186/ej.2020.24.3.11 


\section{Introduction}

The buckling behavior of a composite plate structure depends on a number of parameters i.e. plates: dimensions, strength, fixing and others such as the heat conduction of the plate. This behavior also depends on the mechanical properties of the plate material at a given temperature. Therefore in order to raise the temperature at which buckling occurs the mechanical properties of the composite material must be modified. Most of the research worked towards altering the mechanical properties by growing the fiber refinement volume fraction or improving the composite with stronger fibre.

In 1998 the method for evaluating the effect of variance in temperature on buckling behavior on a plate structured laminated composite material was proposed by P. S. Simelane [1]. In addition, the analysis covered the investigation effect of thermal expansion on the composite using modeling and finite elements

In 2001, R. Rikards et al. [2], the model used to investigate the component structure of the composite plate and the vibration of the modified finite element. The same year was M. K. Singha et al. [3] included a post-buckling model of nonlinear equation and studied, in addition to the impact of various boundary conditions, the thermal effect on post-buckling compliance of a composite laminated plate.

In 2006, S. Han et al. [4], the effect of a combined load on the composite laminated platform structure postbuckling behavior. If, in the ground, lateral and compressive, the loads applied to the board. The paper showed that the composition of the composite plate was influenced by various loads and layers.

In 2009, A. Kumar R. [5], has provided a study of the effects on buckling behavior of composite laminated plates of tissue fibers with epoxy resin. The buckling activity of the plates with different parameters as cutout shape, fiber orientation, aspect ratio and other parameters has also been assessed.

In addition, the paper included an investigation into the buckling behaviour for clamped two edges and free for the remaining two edges of the plate. M. Al-Waily et al. [6-9] studied the buckling behaviour for plate with effect of natural fiber, and different powder reinforcement, and in 2018, M. A. Al-Shammari et al. [10], presented an investigation into the buckling characterization of a honeycomb sandwich plate structure with various core dimensions. Also, in 2018, A. A. Hamzah et al. [11], investigated the effect for thermal loading on the dynamic behavior for shell structure. The work included the determination of the natural frequency for cylindrical shell structure with different temperature effects. The results are calculated by using numerical technique using finite the element technique for vibration analysis shell structure including the effects of temperature.

M. R. Ismail et al. [12], presented an experimental study on the effect of different powders as reinforcement materials on buckling for hyper composite plate structure, with delamination influence.

Recently, in 2019, P. K. Choudhary et al., [13], demonstrated the effect of cutout on the thermal buckling for composite plate. The research covered the analysis the buckling behavior for composite plate structure, with different fiber orientations. Some related works were achieved by [14-17].

From previous work, it can be concluded that fiber or powder when used as reinforcement increases the buckling load of plate with a value that depends on the volume fraction of reinforcement, the increase in buckling load values did not exceed $20 \%$ with volume fraction for reinforcement fiber $40 \%$. Therefore, the modified thermal buckling behavior of plate by Nano particle reinforcement with volume fraction does not exceed $1 \%$. It was learned from the use of fiber or powder as a reinforcement, that the thermal buckling loading are up to not above $20 \%$ and reinforcements in the fraction of fiber volume to not exceed $40 \%$.

In the previous papers submitted, reinforcing of a high volume fraction powder or fiber is required for changing the buckling load, but with Nano particles, the mechanical characteristics and the buckling behavior can be modified by $1 \%$ of volume fraction. To study the effect of nanoparticles on thermal buckling behavior, there are two methods available, firstly an analytical approach using the general equation to buckle the composite layer, and the second is the numerical method with the aid of Ansys; and then the results evaluate show the agreement between the meth and the end product method. The results of this analysis are compared.

In this work, based upon the previous researches findings, an analytical solution is suggested to predict the thermal buckling load for composite plates reinforced with Carbon Nano Particles using an experimental results from a previous work and will be verified numerically using the finite element method and employing the Ansys Package. In this respect, reinforcement is required to alter a load buckling by means of a high volume of powder or fiber, but the mechanical characteristics and behavior of buckling with a $1 \%$ of volume fraction can be changed with Nano particles. For the analysis of Nano-particles reinforcement effects on thermalbuckling behavior.

\section{Analytical Method}

The analytical method calculates the thermal expansion for composite materials reinforced with Nano particle materials; then evaluates the buckling behavior equation for orthotropic plate structure with various volumes for the Nano materials effect. The investigation included derivation of the general equation of motion with $z$-direction of plate deformation, as well as axial applied buckling load effect.

The mechanical properties of the composite material, obtained from previous research [18], were substituted in the equation to determine buckling load, so that the 
thermal expansion of the composite material can be evaluated by deriving the equation for it.

\subsection{Calculating Mechanical and Thermal Properties}

The thermal expansion coefficient of the Nano-resin composite material can be calculated from, [19],

$$
\alpha_{\mathrm{c}}=\frac{1}{2} \alpha_{l}+\frac{1}{2} \alpha_{t}
$$

where $\forall_{\mathrm{r}} \forall_{\mathrm{n}}$ are volume fraction; $\varrho_{\mathrm{r}}, \varrho_{\mathrm{n}}$ are mass density; $\alpha \mathrm{r}, \alpha \mathrm{n}$ are thermal expansion, for resin and Nano materials, respectively. Therefore, the thermal expansion coefficient of composite materials, which is a combination of: woven reinforcement fiber and composite resin reinforced by Nano particles, can be evaluated by,

$$
\alpha_{\mathrm{c}}=\frac{1}{2} \alpha_{l}+\frac{1}{2} \alpha_{t}
$$

where

$$
\begin{aligned}
\alpha_{l} & =\frac{\left(\alpha_{f} E_{f} \forall_{f}+\alpha_{m} E_{m} \forall_{m}\right)}{\left(E_{f} \forall_{f}+E_{m} \forall_{m}\right)} \\
\alpha_{t} & =\left(\alpha_{f} \forall_{f}+\alpha_{m} \forall_{m}\right) \\
& +\frac{\left(v_{f} E_{m}-v_{m} E_{f}\right)}{\left(\forall_{m} E_{m}+\forall_{f} E_{f}\right)}\left(\alpha_{f}-\alpha_{m}\right) \forall_{m} \forall_{f}
\end{aligned}
$$

For, $\alpha_{\mathrm{f}}, \alpha_{\mathrm{m}}$ are thermal expansion, $\mathrm{E}_{\mathrm{f}}, \mathrm{E}_{\mathrm{m}}$ are modulus of elasticity, $\forall_{\mathrm{f}}, \forall_{\mathrm{m}}$ are volume fractions, and, $\nu_{\mathrm{f}}, \nu_{\mathrm{m}}$ are Poisson's ratio, for reinforcement woven fiber and Nano-resin materials, respectively.

The modulus of elasticity was evaluated for Nanoresin composite $\left(\mathrm{E}_{\mathrm{c}}\right)$ by implementing each modulus of elasticity for the materials that made up this composite material into the following equation,

$$
E_{c}=\frac{1}{2}\left(E_{f} \forall_{f}+E_{m} \forall_{m}+\frac{E_{f} E_{m}}{\left(E_{f} \forall_{m}+E_{m} \forall_{f}\right)}\right)
$$

The Nano-resin modulus of elasticity $\left(\mathrm{E}_{\mathrm{m}}\right)$ for composite matrix (a combination of polyester resin and Nano carbon multi wall tube material) was obtained from Eq. (3) by substituting $\left(E_{C}\right)$ that was calculated experimentally, [20], presented in Table 1. The thermal expansion and mechanical properties for the materials used for composite materials are presented in Table 2, [21].

The mechanical properties for composite materials reinforced with Nano plate structure can be used from previous researches by using experimental technique, [20], and, thermal expansion for the composite material, combined from polyester resin materials and reinforced by woven glass fiber and carbon multi wall tube Nano particle materials can be calculated by using Eq. (2), as shown in Table 1 for various Nano volume fraction effect and $15 \%$ reinforcement woven fiber. In addition, the Poisson's ratio for the materials is $\nu_{c}=0.33$. Also, Poisson's ratio for Nano-resin materials is assumed to be, $\nu_{\mathrm{m}}=0.35$.

Table 1. Mechanical and thermal characterizations for composite materials with various nano particle reinforcement materials.

\begin{tabular}{|c|c|c|}
\hline $\begin{array}{c}\text { Nano Volume } \\
\text { Fraction } \\
\boldsymbol{\forall}_{\mathbf{n}}(\%)\end{array}$ & $\begin{array}{c}\mathbf{E}_{\mathbf{c}} \\
\mathbf{( G P a )}\end{array}$ & $\begin{array}{c}\text { Thermal Expansion } \\
\text { Coefficient } \\
\left.\boldsymbol{\alpha}_{\mathbf{c}} \mathbf{(}^{\mathbf{o}} \mathbf{C}^{-\mathbf{1}}\right)\end{array}$ \\
\hline 0.0 & 9.8 & $5.35 \times 10^{-5}$ \\
\hline 0.2 & 10.9 & $5.14 \times 10^{-5}$ \\
\hline 0.4 & 13.7 & $4.42 \times 10^{-5}$ \\
\hline 0.6 & 16.8 & $3.83 \times 10^{-5}$ \\
\hline 0.8 & 19.3 & $3.06 \times 10^{-5}$ \\
\hline 1.0 & 21.2 & $2.27 \times 10^{-5}$ \\
\hline
\end{tabular}

Table 2. Thermal expansion for composite combined materials.

\begin{tabular}{|c|c|c|c|}
\hline \multirow{2}{*}{$\begin{array}{c}\text { Materials } \\
\text { Properties }\end{array}$} & \multicolumn{3}{|c|}{ Materials } \\
\cline { 2 - 4 } & Polyester & E-Glass & $\begin{array}{c}\text { Nano } \\
\text { Carbon }\end{array}$ \\
\hline$\alpha\left({ }^{\circ} \mathrm{C}^{-1}\right)$ & $8 \times 10^{-5}$ & $\begin{array}{c}0.5 \times \\
10^{-5}\end{array}$ & $\begin{array}{c}0.02 \times \\
10^{-5}\end{array}$ \\
\hline$\rho\left(\mathrm{kg} / \mathrm{m}^{3}\right)$ & 1200 & 2600 & 1750 \\
\hline $\mathrm{E}(\mathrm{GPa})$ & 4 & 74 & $/$ \\
\hline$v$ & 0.4 & 0.25 & $/$ \\
\hline
\end{tabular}

\subsection{Buckling Investigation for Plate Structure}

After evaluating the mechanical and thermal properties for composite materials with various Nano reinforcement effect, the general equation for thermal buckling behavior of plate structure is derived.

Figure 1 shows a plate element subjected to an axial force per unit length in $\mathrm{x}$ and $\mathrm{y}$-directions and shear force per unit length. Figures 2 and 3 demonstrates the internal forces and moments per unit length resulted from bending loads $\mathrm{f}(\mathrm{x}, \mathrm{y}, \mathrm{t})$. Figures 4 and 5 show the deformation shape for plate elements in $x z$ and $y z$ respectively, [22]. 


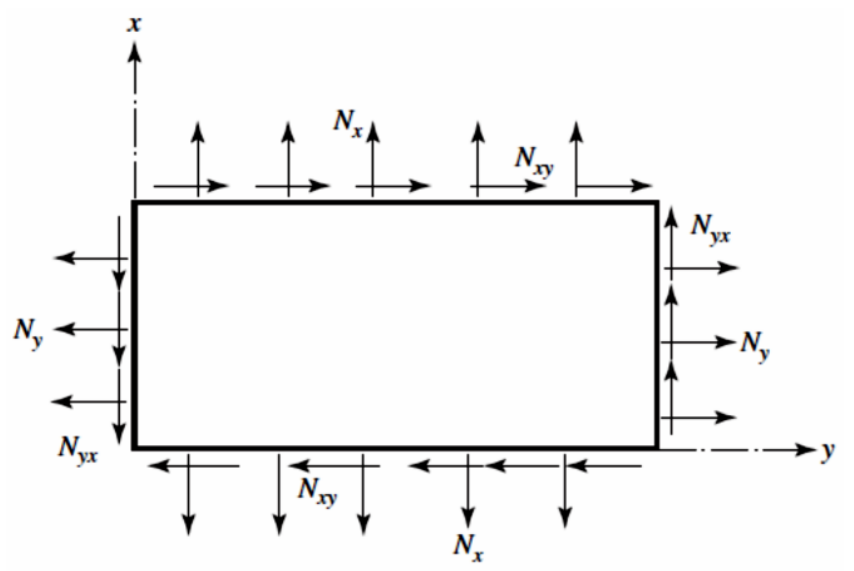

Fig. 1. Plate structure subjected to axial loading.

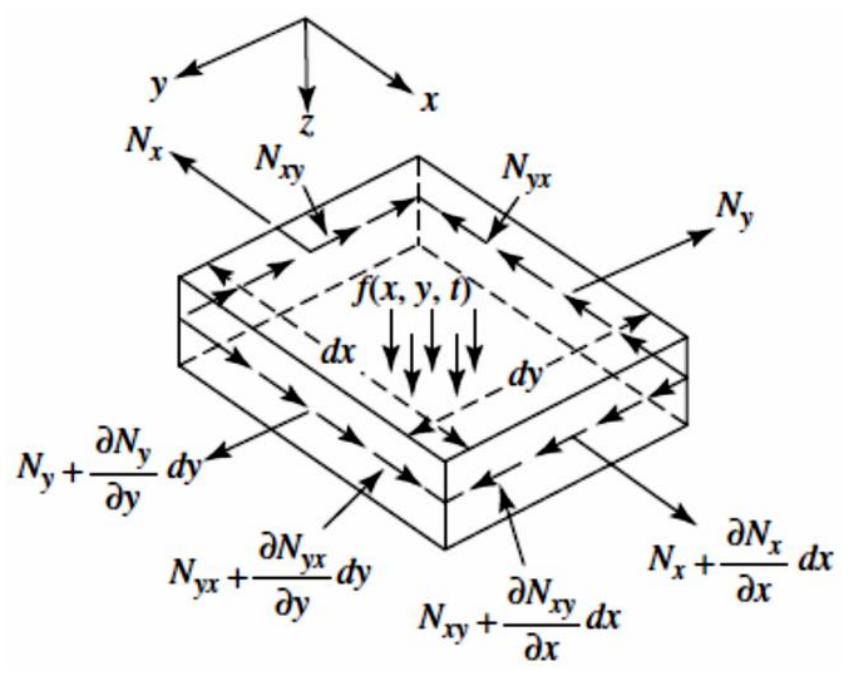

Fig. 2. Load acting at in-plane on plate structure sides.

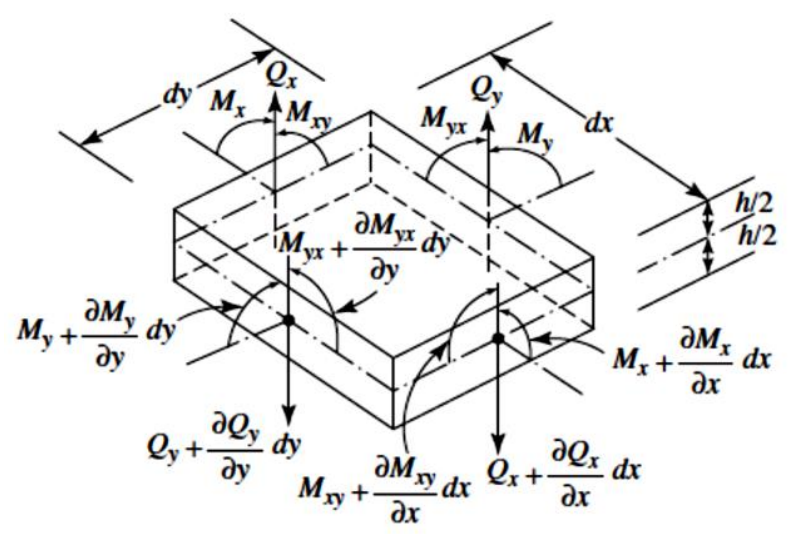

Fig. 3. Shear load and moment acting on plate structure sides.
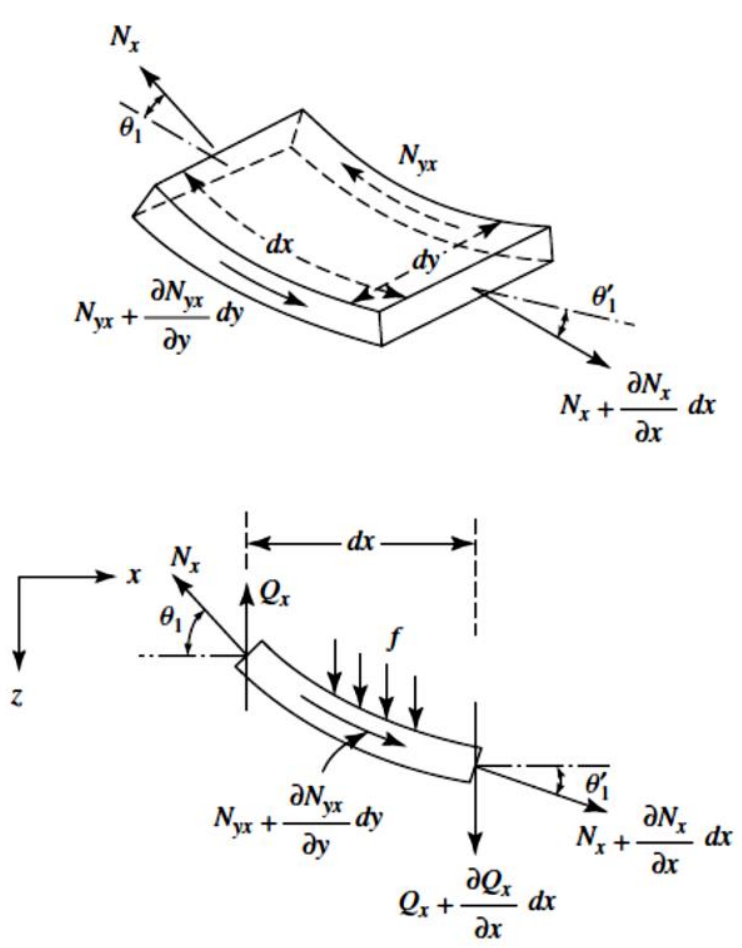

Fig. 4. xz-plane deformation for plate structure.
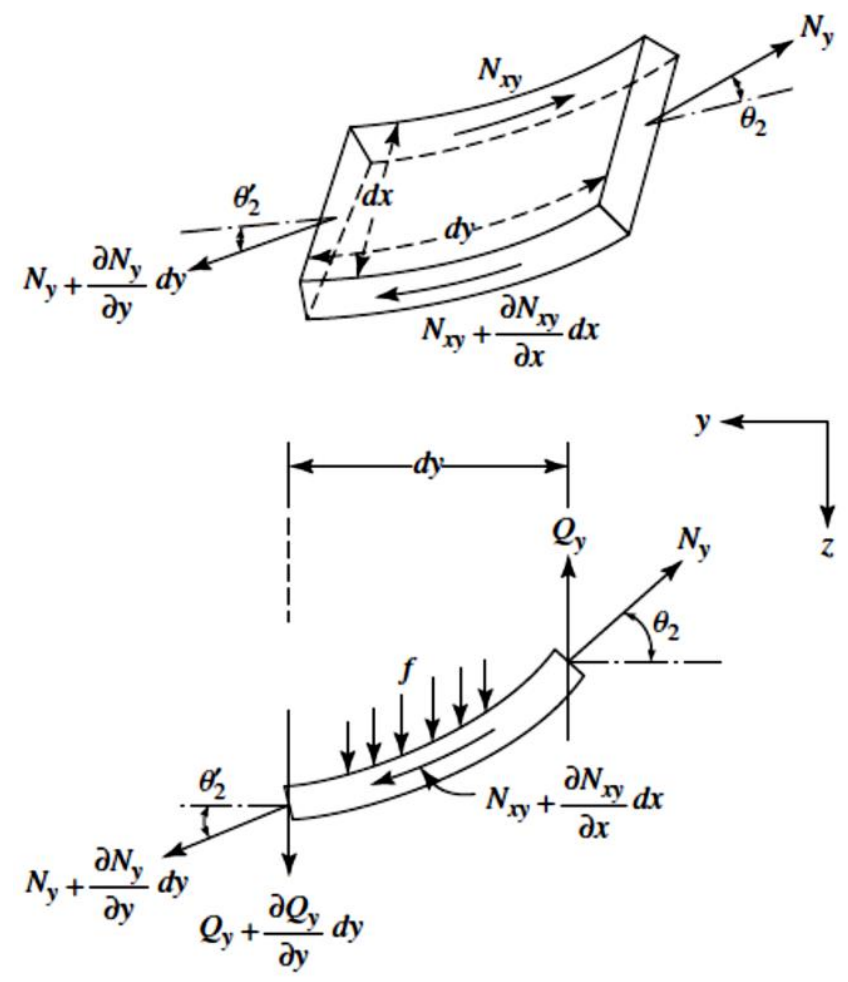

Fig. 5. yz-plane deformation for plate structure.

Thus, by summating moment and force acting on the plate side in $\mathrm{x}, \mathrm{y}$ and $\mathrm{z}$-direction, obtain the general equilibrium equation for plate structure with axial load as in [22]. 
$\frac{\partial Q_{x}}{\partial x}+\frac{\partial Q_{y}}{\partial y}+N_{x} \frac{\partial^{2} w}{\partial x^{2}}+N_{\mathrm{y}} \frac{\partial^{2} w}{\partial y^{2}}+2 N_{\mathrm{xy}} \frac{\partial^{2} w}{\partial \mathrm{x} \partial \mathrm{y}}=0$

where $Q_{x}$ and $Q_{y}$ are the forces action on plate in $z$ direction, and can be calculated from,

$Q_{x}=-D\left(\frac{\partial^{3} w}{\partial x^{3}}+\frac{\partial^{3} w}{\partial y^{2} \partial x}\right)$

$Q_{y}=-D\left(\frac{\partial^{3} w}{\partial x^{2} \partial y}+\frac{\partial^{3} w}{\partial y^{3}}\right)$

where $\mathrm{w}$ is bending deflection for plate in $\mathrm{z}$-direction. By substituting Eq. (5) into Eq. (4) obtain,

$$
\begin{aligned}
& D\left(\frac{\partial^{4} \mathrm{w}}{\partial \mathrm{x}^{4}}+2 \frac{\partial^{4} w}{\partial x^{2} \partial y^{2}}+\frac{\partial^{4} \mathrm{w}}{\partial \mathrm{y}^{4}}\right) \\
& =\left(N_{x} \frac{\partial^{2} w}{\partial x^{2}}+N_{\mathrm{y}} \frac{\partial^{2} w}{\partial y^{2}}+2 N_{\mathrm{xy}} \frac{\partial^{2} w}{\partial \mathrm{x} \partial \mathrm{y}}\right)
\end{aligned}
$$

where $\mathrm{D}$ is the rigidity flexural for plate, and evaluated as,

$$
D=\frac{E_{c} h^{3}}{12\left(1-v_{c}^{2}\right)}
$$

And, $\mathrm{N}_{\mathrm{x}}, \mathrm{N}_{\mathrm{y}}$ and $\mathrm{N}_{\mathrm{xy}}$ are buckling loads per unit length applied on plate structure. Therefore, to evaluate the thermal buckling, assuming the thermal applied load equal to the mechanical buckling load in $\mathrm{x}$ and $\mathrm{y}$ directions, [23]. Then get,

$N_{x}=N_{y}=-\frac{E_{c}}{\left(1-v_{c}\right)} \alpha_{c} h \cdot \Delta T_{\text {buckling }}$

$N_{x y}=0$

where $\Delta \mathrm{T}_{\text {buckling }}$ is buckling the temperature that can be applied on the plate structure, and $\mathrm{h}$ is the plate thickness. Then, by substituting Eq. (8) into Eq. (6) obtain,

$$
\begin{aligned}
& D\left(\frac{\partial^{4} \mathrm{w}}{\partial \mathrm{x}^{4}}+2 \frac{\partial^{4} w}{\partial x^{2} \partial y^{2}}+\frac{\partial^{4} \mathrm{w}}{\partial \mathrm{y}^{4}}\right) \\
& +\frac{E_{c}}{\left(1-v_{c}\right)} \alpha_{c} h \cdot \Delta T_{\text {buckling }}\left(\frac{\partial^{2} w}{\partial x^{2}}+\frac{\partial^{2} w}{\partial y^{2}}\right)=0
\end{aligned}
$$

Thus, to solve Eq. (9) requires evaluating the plate behavior as a function of $\mathrm{x}, \mathrm{y}$, by assuming the general behavior of plate with general solution, as, [22],

$w(x, y)$

$=A_{1} \sin \alpha x \cdot \sin \beta y+A_{2} \sin \alpha x \cdot \cos \beta y$

$+A_{3} \cos \alpha x \cdot \sin \beta y+A_{4} \cos \alpha x \cdot \cos \beta y$

$+A_{5} \sinh \theta x \cdot \sinh \emptyset y+A_{6} \sinh \theta x \cdot \cosh \emptyset y$

$+A_{7} \cosh \theta x \cdot \sinh \varnothing y+A_{8} \cosh \theta x \cdot \cosh \varnothing y$ where $A_{1}$ to $A_{8}$ and $\alpha, \beta, \theta$, and $\varnothing$ are constants. Therefore, by substituting the boundary supported for plate, depending on the supported types can calculate its constant, for simply supported plate on all sides of the plate are satisfied, as,

$\left.w(x, y)\right|_{x=0, a}=\left.\left(\frac{\partial^{2} w}{\partial x^{2}}+v_{c} \frac{\partial^{2} w}{\partial y^{2}}\right)\right|_{x=0, a}=0$

$\left.w(x, y)\right|_{y=0, b}=\left.\left(\frac{\partial^{2} w}{\partial y^{2}}+v_{c} \frac{\partial^{2} w}{\partial x^{2}}\right)\right|_{y=0, b}=0$

Then by substituting boundary conditions, Eq. (11) into Eq. (10), obtain the behavior for plate structure as,

$w(x, y)=A_{1} \sin \frac{m \pi x}{a} \cdot \sin \frac{m \pi y}{b}$

where $\mathrm{n}$ and $\mathrm{m}$ are integer using $\mathrm{n}, \mathrm{m}=1,2, \ldots$, and, $\mathrm{a}$ and $\mathrm{b}$ are length and width for plate. Now, by substituting Eq. (12) into Eq. (9), obtain,

$\Delta T_{\text {buckling }}=\frac{D\left(\left(\frac{m \pi}{a}\right)^{4}+2\left(\frac{m \pi}{a}\right)^{2}\left(\frac{m \pi}{b}\right)^{2}+\left(\frac{m \pi}{b}\right)^{4}\right)\left(1-v_{c}\right)}{\left(E_{c} \alpha_{c} h\left(\left(\frac{m \pi}{a}\right)^{2}+\left(\frac{m \pi}{b}\right)^{2}\right)\right)}$

Finally, from Eq. (13), the thermal buckling load can be calculated. This can be applied on plate structure with various Nano particle materials reinforcement of composite plate, combined from woven reinforcement fiber and resin materials. In order to calculate its thermal effect, it is required to build a computer program by using FORTRAN language, as shown in Fig. 6, which can be used to calculate the mechanical and thermal properties for composite materials, from Eq. (1) to (3), and then, calculating the thermal buckling, $\Delta \mathrm{T}_{\text {buckling }}$, from Eq. (13).

\section{Numerical Method}

The numerical technique used to evaluate the buckling behavior for composite plate reinforced by Nano particle materials is divided into two parts. The first, investigates the best number of elements and element type that must be achieved to obtain the best results for buckling application, and the second is to investigate the solution for buckling plate with various volume fractions for reinforced Nano particle plate structure.

The results of the numerical findings are also evaluated using a general equation of the thermal buckling plate behavior derived from the mathematical model of the buckling plate. The first part of numerical engineering therefore was important to select the correct element form for composite structure buckling analyzes. The best form of variable can therefore be used, as shown in the Fig. 7, [24], to achieve the best results (Shell-281), [25]. This module has the following features: 


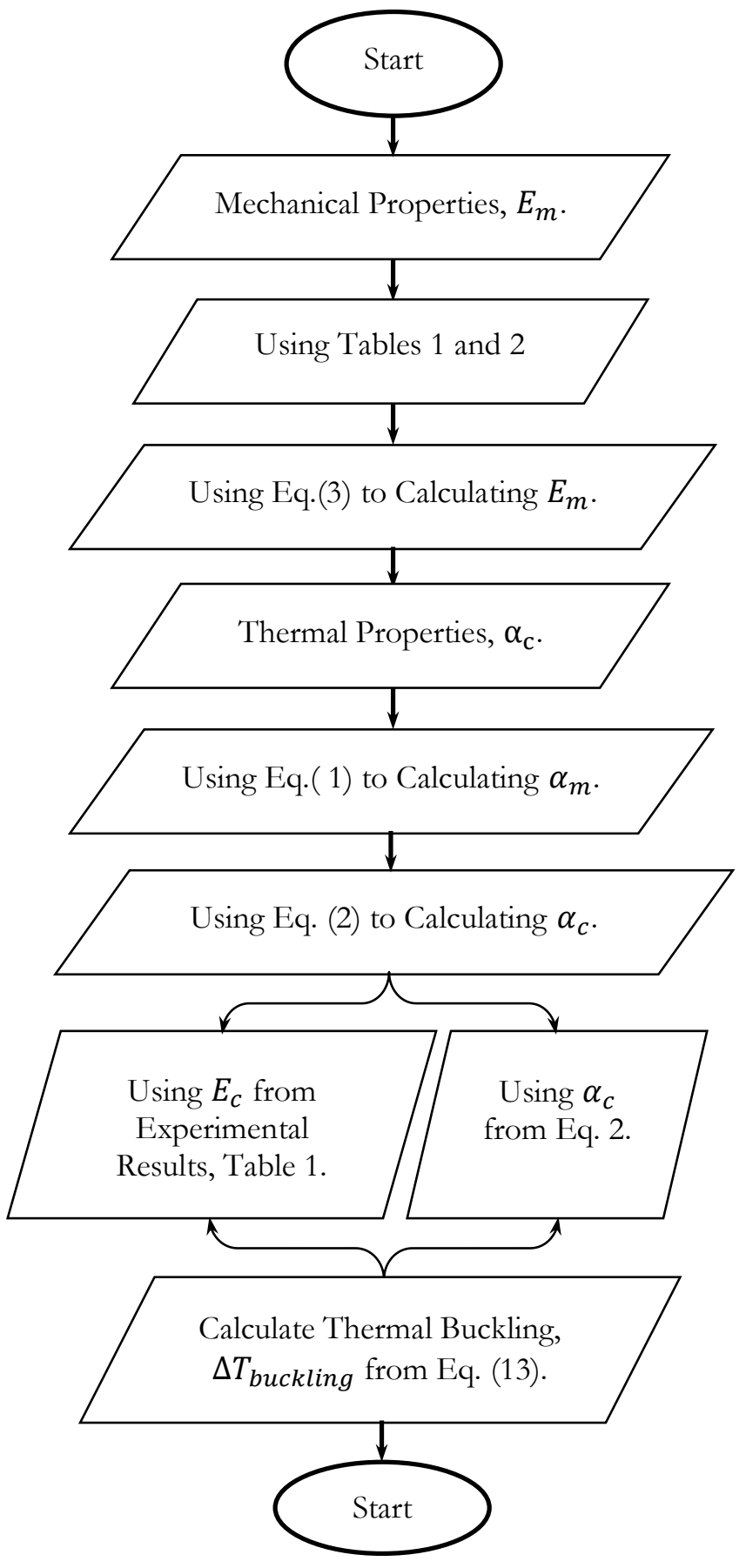

Fig. 6. Computer flow chart to calculate thermal load.

1. Number of elements is 8-nodes with 6-degrees of freedom at each node in the direction of translation and rotation.

2. Theoretical analyses using the first order shear deformation theory as shown in Fig. 8

3. The element is used for thick structure, composite and sandwich structure.

4. The element is used for linear and non- linear structural behavior,

Therefore, due to the characteristics of shell 281 element, then, this element can be used for analyzing the buckling behavior for composite plate. After selecting the types of elements to mesh the buckling model, the number of elements required must be selected to give best results for the selected case. Then, by using the finite element technique the number of elements for plate must be selected, [26-27], which gives the best thermal buckling results with different Nano particle reinforcement volume fraction effect, are about 2000 elements, and nodes number are 12000, depending on mesh generation presenting plate buckling, [28], as shown in Fig. 9.

Ultimately, the thermal buckling load of the platform structure with various Nano-reinforcement effects shall be evaluated after selecting the appropriate number of elements and node number using the mechanical and thermal characteristics provided in Table 2. It shall then be compared to results obtained analytically with Eq. (13).

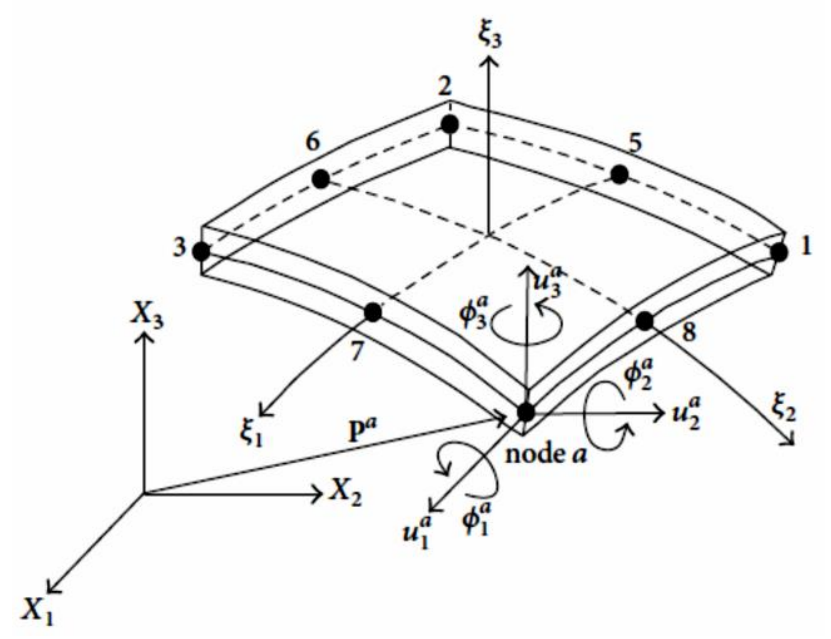

Fig. 7. Shell-281, 8-nodes and 6-degree, geometry.

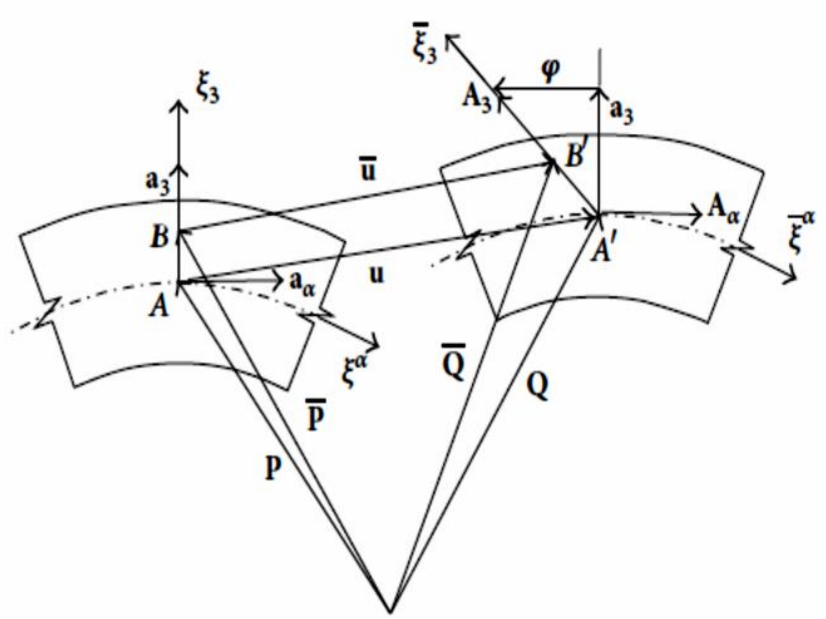

Fig. 8. Deformation behavior with first order shear deformation theory. 


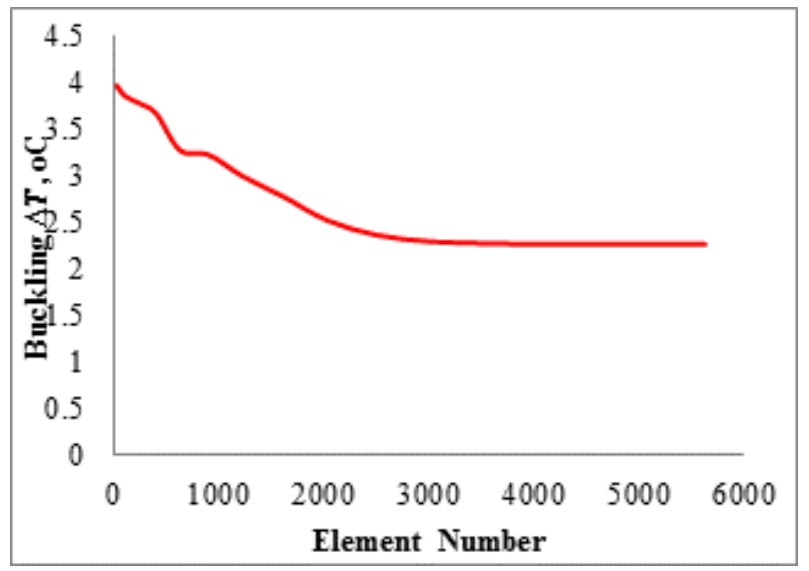

a. $0 \%$ Nano particle materials reinforcement

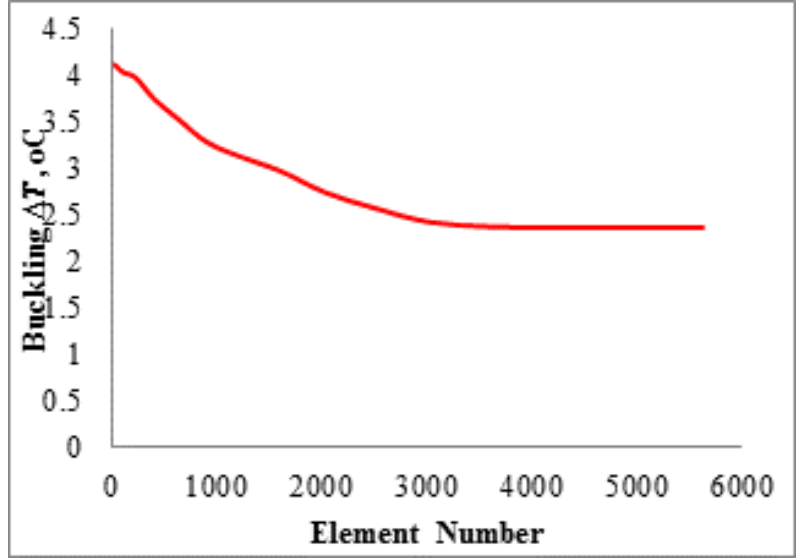

b. $0.2 \%$ Nano particle materials reinforcement

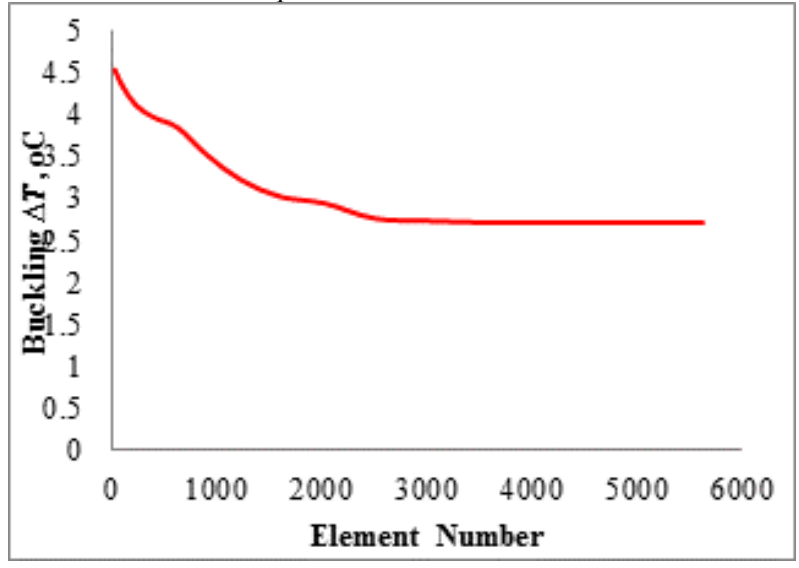

c. $0.4 \%$ Nano particle materials reinforcement

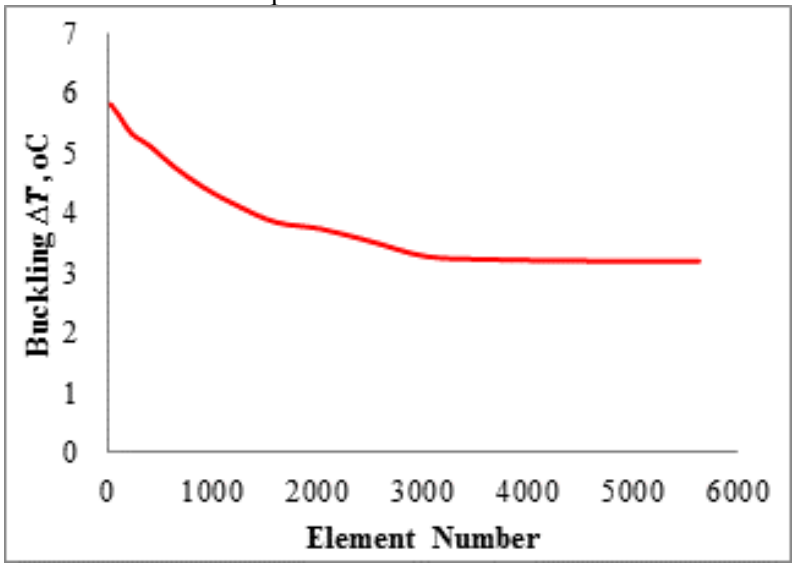

d. $0.6 \%$ Nano particle materials reinforcement

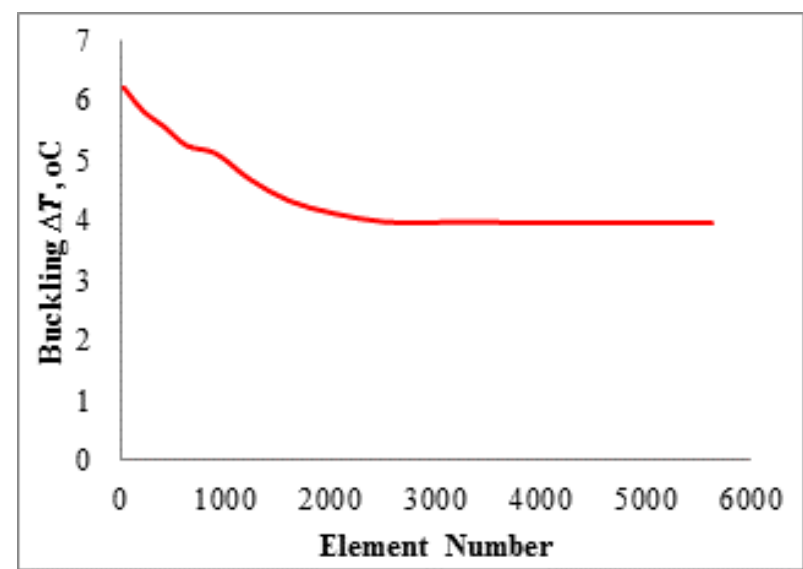

e. $0.8 \%$ Nano particle materials reinforcement

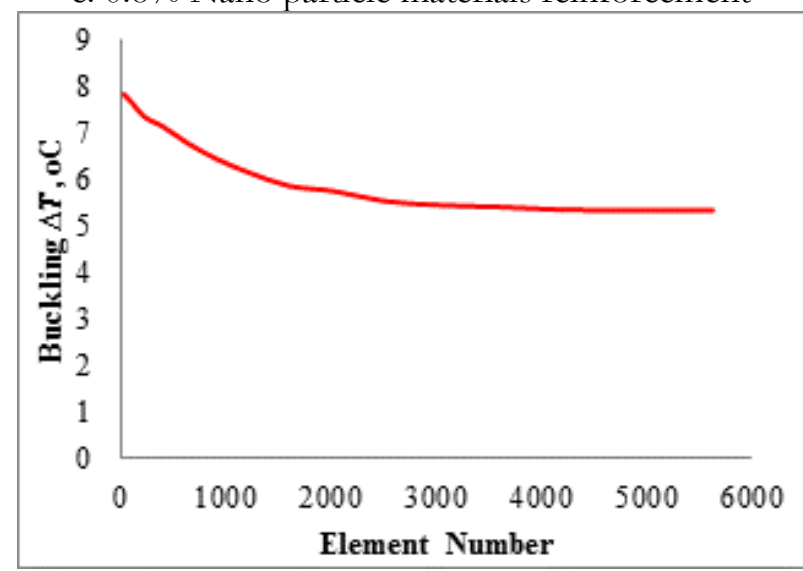

f. 1\% Nano particle materials reinforcement

Fig. 9. Selecting best element and node number for plate structure, for various Nano particle reinforcement effect.

\section{Results and Discussion}

The results of the research included solving the general equation for buckling analytically so as to predict the buckling behavior for the plate composite reinforced with Nano- particles due to the plates being subjected to heat.

Such findings are also included the numerical assessment and a comparison was made with the use of a simply supported plate on all sides and edges with different plate aspect ratios as follows,

i. Length of plate $a=0.25 \mathrm{~m}$, width of plate $\mathrm{b}=0.5 \mathrm{~m}$, thickness of plate $\mathrm{h}=5 \mathrm{~mm}$ and aspect ratio, $\mathrm{AR}=0.5$.

ii. Length of plate $a=0.5 \mathrm{~m}$, width of plate $\mathrm{b}=0.5 \mathrm{~m}$, thickness of plate $\mathrm{h}=5 \mathrm{~mm}$ and aspect ratio, $\mathrm{AR}=1$.

iii. Length of plate $\mathrm{a}=1 \mathrm{~m}$, width of plate $\mathrm{b}=0.5 \mathrm{~m}$, thickness of plate $\mathrm{h}=5 \mathrm{~mm}$ and aspect ratio, $\mathrm{AR}=2$.

Also, the mechanical and thermal properties used in analytical and numerical solutions are as presented in Table 2.

The study includes a comparison of results evaluated with various aspect ratios and Nano particle effect, as shown in Fig. 10, for aspect ratios 0.5, 1, and 2, using different volume fractions. From this figure it can be seen that the analytical solution for thermal buckling load gives good results when compared with numerical results, which were evaluated by finite element method, where 
the maximum discrepancy evaluated is $(2.49 \%)$, for various Nano volume fraction effect.

After examining the proposed analytical method, it is possible to implement this solution on different plates with the same boundary conditions. Figures 11 and 12 show how the materials are affected. Both figures show that the buckle rises with the temperature increase and continues to double that of Nano.

The results also showed that plates with small dimensions as well as a small aspect ratio are exposed to changes due to temperatures higher than that of larger plates. It can be also noticed that the buckling strength reaches $(65 \%)$ with the presence of Nano which is three times more than without Nano particles.

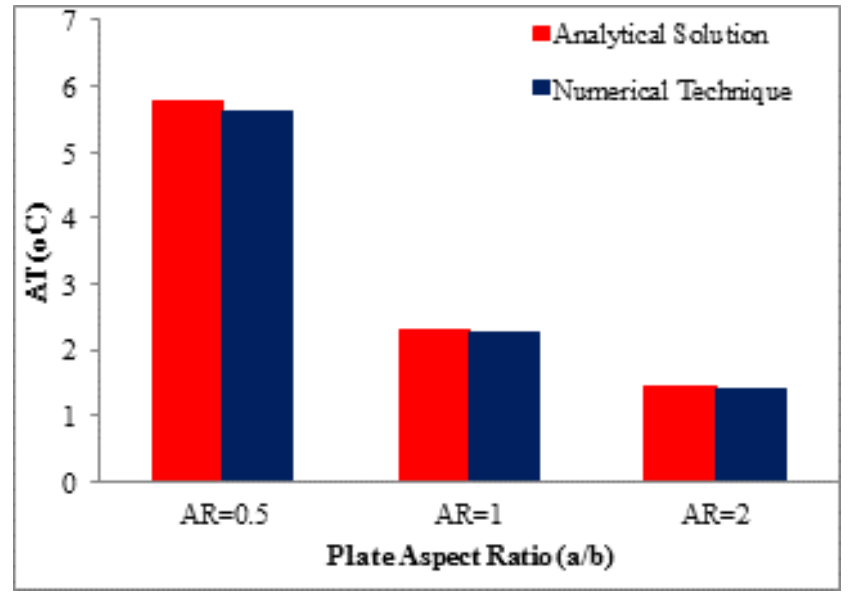

a. Nano Particle Reinforcement, $0 \%$.
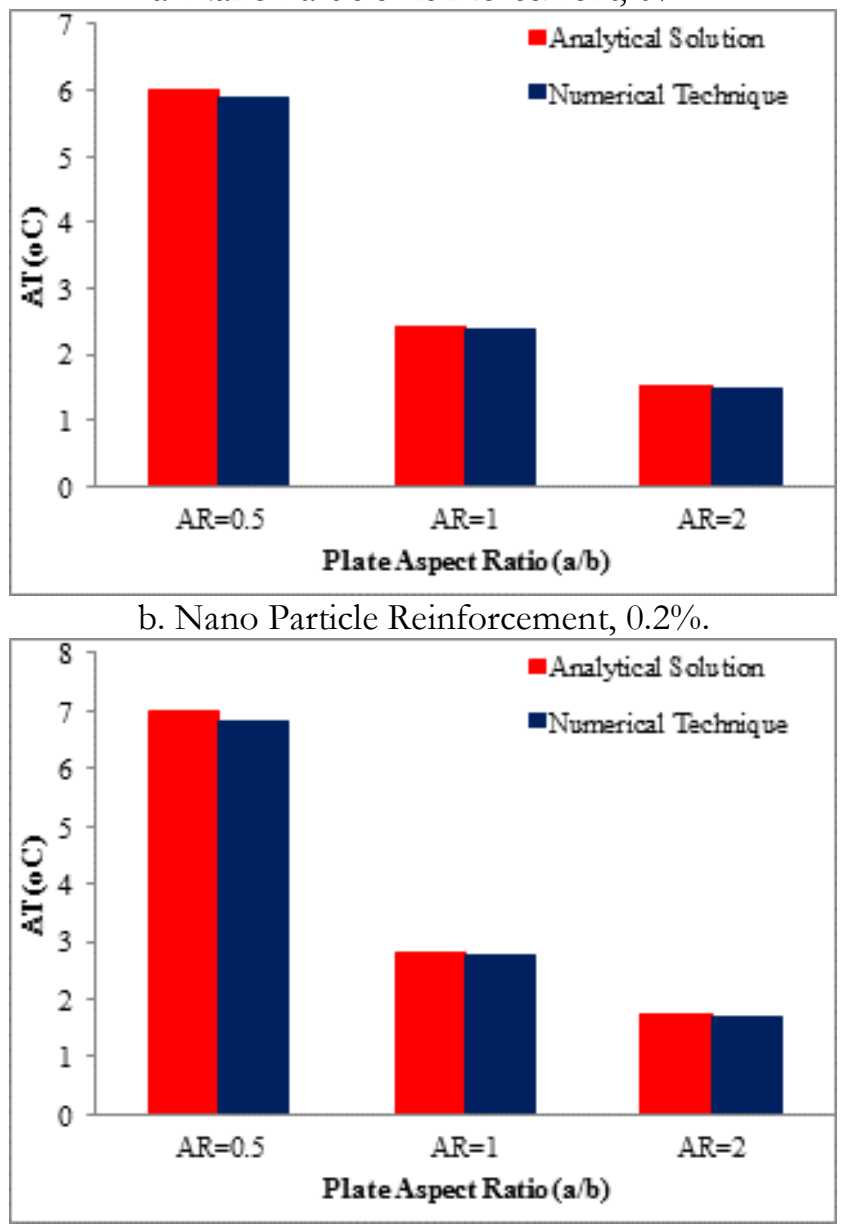

c. Nano Particle Reinforcement, $0.4 \%$.
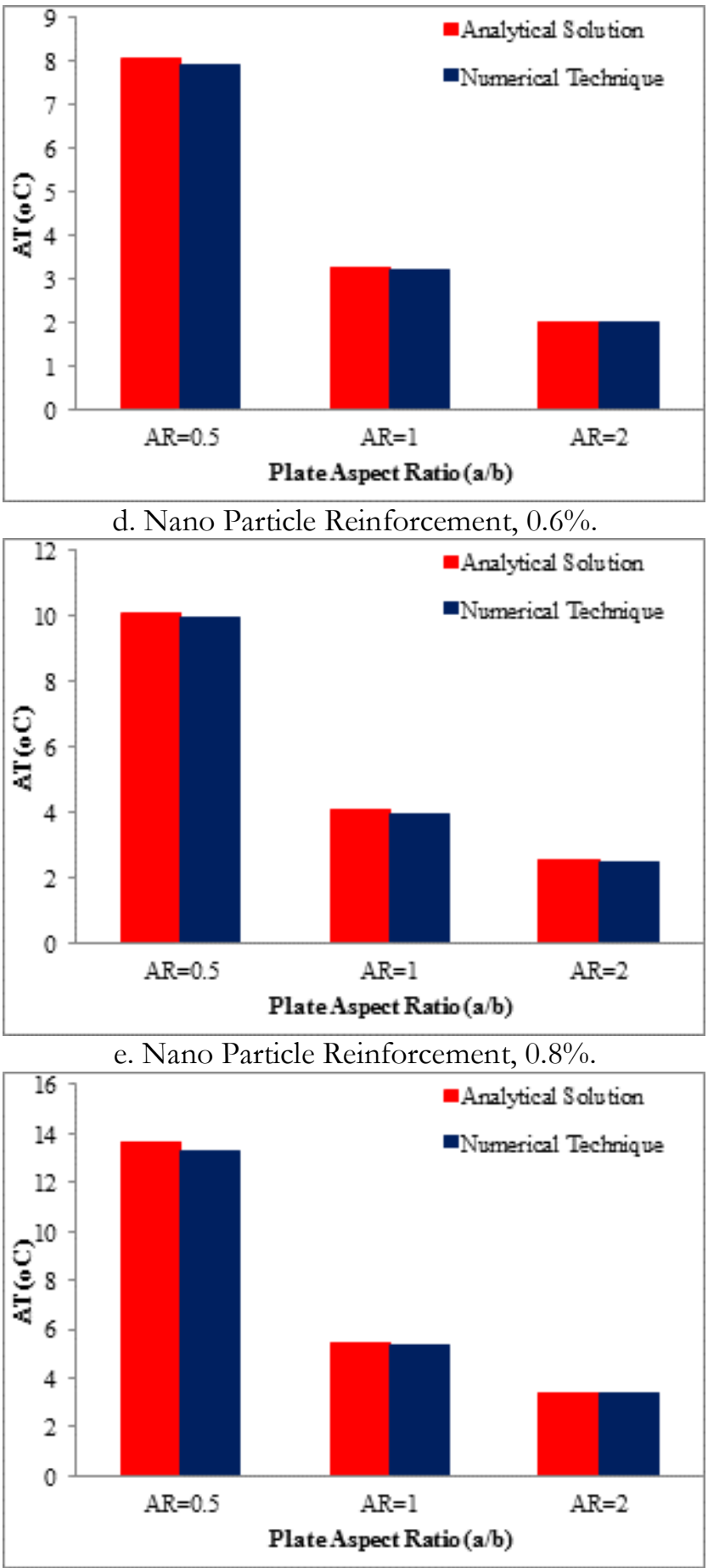

f. Nano Particle Reinforcement, 1\%.

Fig. 10. Comparison for analytical and numerical buckling temperature, with various Nano particle and plate aspect ratio effect. 

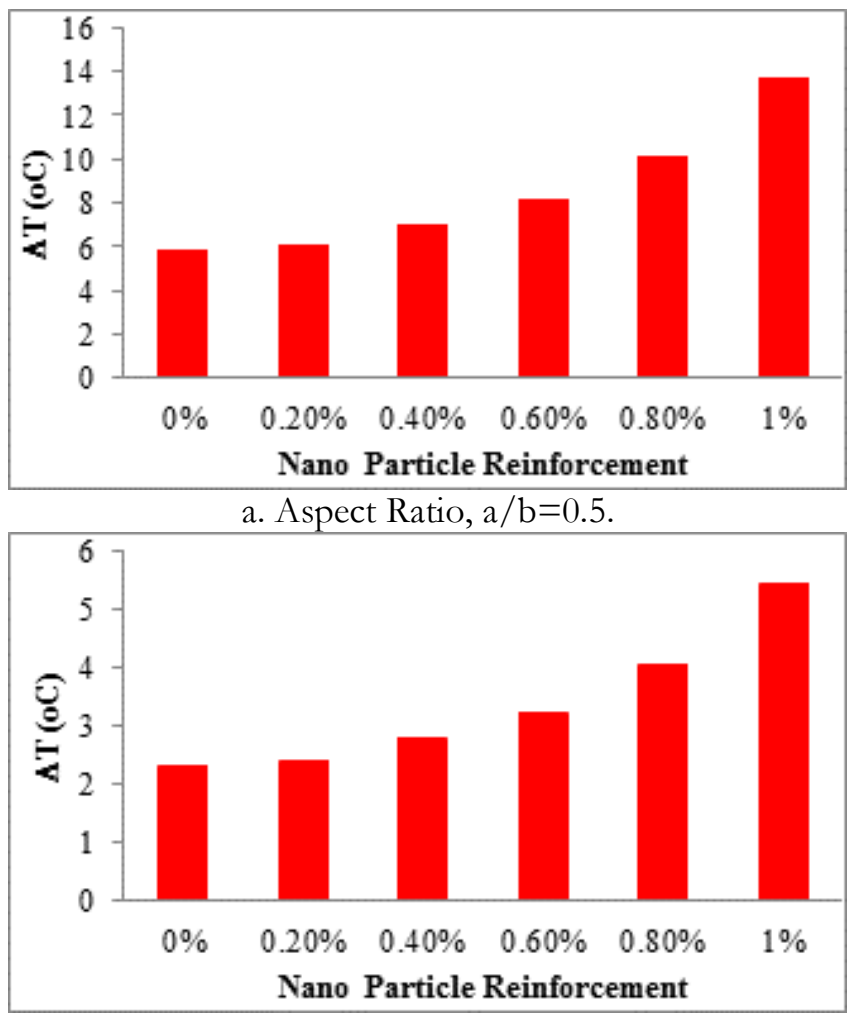

b. Aspect Ratio, a/b=1.

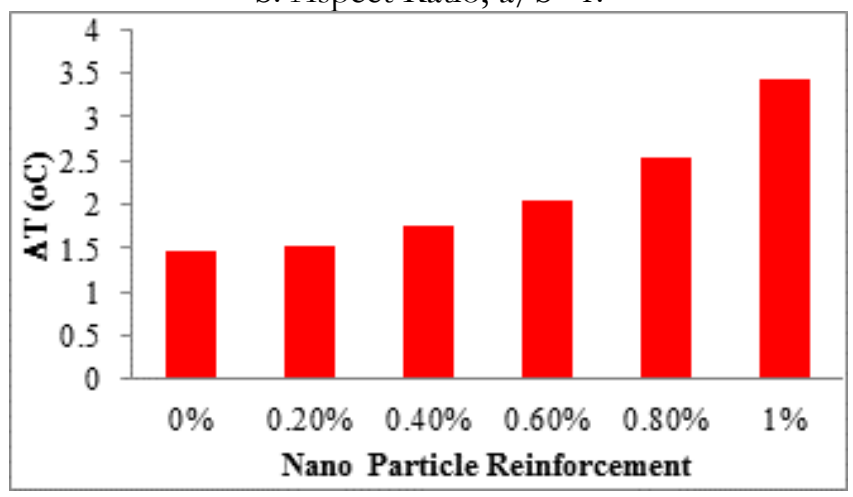

c. Aspect Ratio, $\mathrm{a} / \mathrm{b}=2$.

Fig. 11. Nano particle reinforcement effect on thermal buckling behavior with plate aspect ratio influence

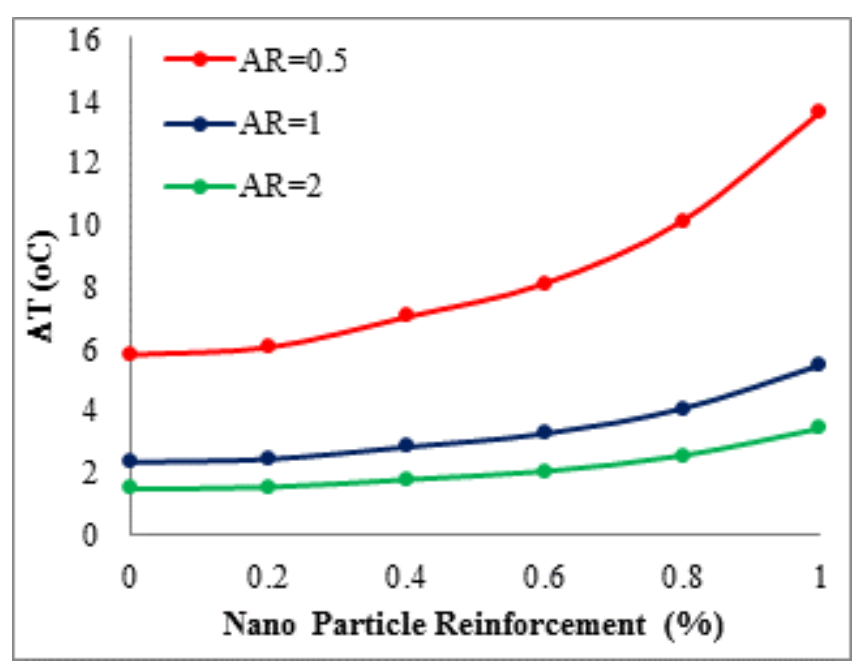

Fig. 12. Plate aspect ratio effect on thermal buckling behavior with various Nano particle reinforcement influence.

\section{Conclusions}

The results for a suggested theoretical and numerical tests of the composite thermal buckling effect clearly assisted with multi-wall strengthening materials of Nano particle carbon dioxide fractions, are,

i. The analytical or numerical methods employed provided a fair difference, where the average error did not lead to $(2.7 \%)$, different Nano materials and different flat aspect ratio.

ii. The strengthening of nano carbon multi wall materials leads to more than double the change in the thermal properties of composite materials without nano or fibre reinforcement.

iii. Heat can be applied to a composite plate structure, without causing a buckling and an increase to more than $(65 \%)$ when reinforced by $1 \%$ Nano carbon multi wall tube carbon materials.

iv. The analytical investigation for thermal buckling load of composite plate structure can be used to calculate the effect of Nano particle reinforcement on buckling behavior for plate.

\section{References}

[1] P. S. Simelane, "Thermal buckling of laminated composite plates," M.Sc. thesis, Department of Mechanical Engineering, Centre for Research in Applied Technology, 1998.

[2] R. Rikards, A. Chate, and O. Ozolinsh, "Analysis for buckling and vibrations of composite stiffened shells and plates," Composite Structures, vol. 51, pp. 361-370, 2001.

[3] M. K. Singha, L. S. Ramachandra, and J. N. Bandyopadhyay, "Thermal postbuckling analysis of laminated composite plates," Composite Structures, vol. 54, pp. 453-458, 2001.

[4] S.-C. Han, S.-Y. Lee, G. Rus, "Postbuckling analysis of laminated composite plates subjected to the combination of in-plane shear, compression and lateral loading," International Journal of Solids and Structures, vol. 43, pp. 5713-5735, 2006.

[5] A. Kumar R, "Buckling analysis of woven glass epoxy laminated composite plate," M.Sc. thesis, Department of Civil Engineering, National Institute of Technology Rourkela, Orissa, India, 2009.

[6] M. J. Jweeg, M. Al-Waily, and A. A. Deli, "Theoretical and numerical investigation of buckling of orthotropic hyper composite plates," International Journal of Mechanical \& Mechatronics Engineering IJMME-IJENS, vol. 15, no. 04, 2015.

[7] M. Al-Waily and Z. A. A. A. Ali, "A suggested analytical solution of powder reinforcement effect on buckling load for isotropic mat and short hyper composite materials plate," International Journal of Mechanical \& Mechatronics Engineering IJMME-IJENS, vol. 15, no. 04, 2015. 
[8] M. Al-Waily, A. A. Deli, A. D. Al-Mawash, and Z. A. A. A. Ali, "Effect of natural sisal fiber reinforcement on the composite plate buckling behavior," International Journal of Mechanical \& Mechatronics Engineering IJMME-IJENS, vol. 17, no. 01, 2017.

[9] J. S. Chiad, M. Al-Waily, and M. A. Al-Shammari, "Buckling investigation of isotropic composite plate reinforced by different types of powders," International Journal of Mechanical Engineering and Technology (IJMET), vol. 09, no. 09, pp. 305-317, 2018.

[10] M. A. Al-Shammari and M. Al-Waily, "Analytical investigation of buckling behavior of honeycombs sandwich combined plate structure," International Journal of Mechanical and Production Engineering Research and Development (IJMPERD), Vol. 08, No. 04, pp. 771-786, 2018.

[11] A. A. Hamzah, H. K. Jobair, O. I. Abdullah, E. T. Hashim, and L. A. Sabri, "An investigation of dynamic behavior of the cylindrical shells under thermal effect," Case Studies in Thermal Engineering, vol. 12, pp. 537-545, 2018.

[12] M. R. Ismail, Z. A. A. A. Ali, and M. Al-Waily, "Delamination damage effect on buckling behavior of woven reinforcement composite materials plate," International Journal of Mechanical \& Mechatronics Engineering IJMME-IJENS, vol. 18, no. 05, 2018.

[13] P. K. Choudhary and P. K. Mahato, "Thermal buckling analysis of laminated composite plates containing an elliptical cutout," in $64^{\text {th }}$ Congress of Indian Society of Theoretical and Applied Mechanics (ISTAM 2019), December 9-12, 2019.

[14] A. F. Izzet and A. A. Mohammed, "Residual strength of composite unprotected steel-deck floor exposed to high temperature (fire flame)," Engineering Journal, vol. 22, no. 1, 2018.

[15] S. A. Bello, J. O. Agunsoye, J. A. Adebisi, N. K. Raji, R. G. Adeyemo, A. G. F. Alabi, and S. B. Hassan, "Flexural performances of epoxy aluminium particulate composites," Engineering Journal, vol. 22, no. 4, 2018.

[16] N. Thanarattanasap, P. Tumawong, T. Sinsawat, E. Chaichana, and B. Jongsomjit, "Polyethylene/bacterial-cellulose biocomposite synthesized via in situ polymerization with zirconocene/MMAO catalyst," Engineering Journal, vol. 23, no. 3, 2019.

[17] M. Thianwiboon, "Optimization of a hybrid carbon/glass composites afterbody of the amphibious plane with finite element analysis," Engineering Journal, vol. 23, no. 5, 2019.
[18] E. N. Abbas, M. J. Jweeg, and M. Al-Waily, "Analytical and numerical investigations for dynamic response of composite plates under various dynamic loading with the influence of carbon multi-wall tube nano materials," International Journal of Mechanical \& Mechatronics Engineering IJMME-IJENS, vol. 18, no. 06, 2018.

[19] M. Mahmoodi and S. M. Hashemi, "Numerical study of natural convection of a nanofluid in Cshaped enclosures," International Journal of Thermal Sciences, vol. 55, pp. 76-89, 2012.

[20] M. Al-Waily and T. J. Ntayeesh, "Influence of multi wall carbon nanotube (MWCNTs) reinforcement on the mechanical properties and vibration behavior of composite plates," in $1^{\text {st }}$ International Conference on Recent Trends of Engineering Sciences and Sustainability, 17-18 May 2017.

[21] D. Gay, S. V. Hoa, and S. W. Tsai, Composite Materials Design and Application. CRC Press LLC, 2003.

[22] S. S. Rao, Vibration of Continuous System. John Wiley and Sons, Inc., 2007.

[23] M. Al-Waily, "Analytical and numerical thermal buckling analysis investigation of unidirectional and woven reinforcement composite plate structural," International Journal of Energy and Environment, vol. 06, no. 02, 2015.

[24] W. Y. Jung and S. C. Han, "An 8-node shell element for nonlinear analysis of shell using the refined combination of membrane and shear interpolation functions," Mathematical Problem in Engineering, vol. 2013, 2013.

[25] R. K. Singh, "Thermal buckling analysis of laminated composite shell panel embedded with shape memory alloy fibre under TD and RID," M.Sc. thesis, National Institute of Technology, Department of Mechanical Engineering, 2014.

[26] M. J. Jweeg, "Application of finite element analysis to rotating fan impellers," doctoral thesis, Aston University, 1983.

[27] M. A. Al-Shammari and M. Al-Waily, "Theoretical and numerical vibration investigation study of orthotropic hyper composite plate structure," International Journal of Mechanical \& Mechatronics Engineering IJMME-IJENS, vol. 14, no. 06, 2014.

[28] M. Al-Waily, E. Q. Hussein, and N. A. A. AlRoubaiee, "Numerical modeling for mechanical characteristics study of different materials artificial hip joint with inclination and gait cycle angle effect," Journal of Mechanical Engineering Research \& Developments (JMERD), vol. 42, no. 04, pp. 79-93, 2019. 


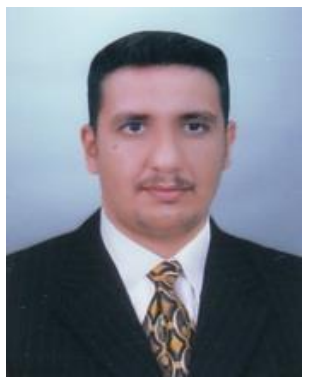

Asst. Prof. Dr. Muhannad Al-Waily, Lecturer at Mechanical Engineering Department, Faculty of Engineering, Al-Kufa University. Ph.D. In Mechanical Engineering/College of Engineering / Alnahrain University /Iraq. - Specialization: Applied Mechanics- Vibration Analysis, Composite Material, Crack Analysis, Health Monitoring, Graduation Date: 2012. M.Sc. In Mechanical Engineering/ College of Engineering/University of Kufa/Iraq • Specialization: Applied Mechanics- Vibration Analysis, Composite Material, Stress Analysis, Graduation Date: 2005. B.Sc. In Mechanical Engineering/ College of Engineering/University of Kufa / Iraq • Specialization: General Mechanics, Graduation Date: 2002.

Research Interests, Vibration Engineering Analysis Study, Plate and Shell Study, Vibration Beam, Plate, Shell Analysis, Stress Analysis Study under Static and Dynamic Loading, Buckling Analysis Study, Composite Materials Study, Fatigue Analysis Study of Engineering Materials, Mechanical Properties of Engineering Materials Study, Control and Stability of Mechanical Application Study, Damage Study (Crack and Delamination Study), Flow Induced Vibration of Pipe, Heat Generation due to Vibration Effect, Rubber Material Study, Prosthetic and Orthotics Study, Friction Stir Welding Study, and other mechanical researches.

Associate Editors, Applied Mechanics Research Center, International Energy and Environment Foundation (IEEF), Najaf, http://www.ijee.ieefoundation.org/, http://www.amrc.ieefoundation.org/, http://www.ieefoundation.org/

Contact: E-mail: muhanedl.alwaeli@uokufa.edu.iq, Mobile: +9647811185334

http://www.uokufa.edu.iq/faculty/staff_sites/en/index.php?muhanedl.alwaeli

https://www.scopus.com/authid/detail.uri?authorId $=55385828500$

https://scholar.google.com/citations? user=XIJJdesAAAAJ\&hl=ar

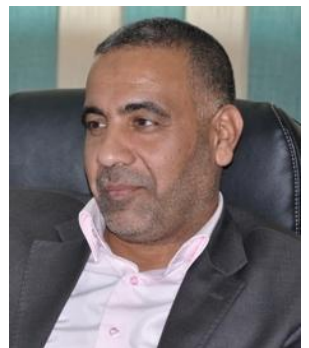

Asst. Prof. Dr. Mohsin A. Al-Shammari, Lecture in University of Baghdad- Faculty of Engineering - Mechanical Engineering Department. Ph.D. In Mechanical Engineering/ University of Technology/ Iraq. - Specialization: Applied Mechanics- Vibration Analysis Study and Composite Material Study-Crack Study, Graduation Date: 2010. M.Sc. In Mechanical Engineering/ College of Engineering/University of Baghdad/Iraq• Specialization: Applied Mechanics- Tribology, Graduation Date: 1997. B.Sc. In Mechanical Engineering/ College of Engineering/University of Baghdad /Iraq - Specialization: General Mechanics, Graduation Date: 1992. Research Interests, Vibration Analysis Study, Stress Analysis Study under Static and Dynamic Loading, Composite Materials Study, Fatigue and Creep Analysis Study of Engineering Materials, Mechanical Properties of Engineering Materials Study, Damage Study (Crack and Delamination Study), Hydrodynamic Lubrication and other mechanical researches.

Contact:dr.alshammari@uobaghdad.edu.iq

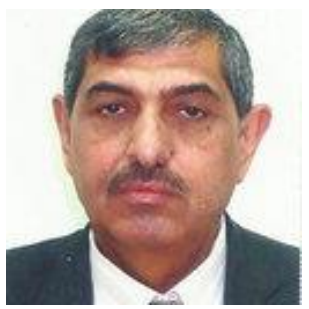

Prof Dr. Muhsin J. Jweeg is a prof. of applied mechanics. He is currently the Dean of the College of Technical Engineering, Al-arahidi University, Prior to this position, head of scientific affairs at Telafer University, he was also a Prof. at AL-Nahrain University, Prostheses and Ortheses Eng. Department, and was a dean of the college of Engineering for the period Oct 2006-Mar 2013. Prof. Jweeg is an author of more than 150 journal paper, three books . He attended international and national conferences and gained an international prize in in India for the best published paper in IMECH 1995, and many national prizes in different occasions. He shared with his colleagues 5 patents, gained the bronze medal in the inventors meeting in Kerbala-Iraq 2017. About 50 Ph.d students graduated under his supervision, applied mechanics, and most of them working in the field of energy and finite element applications.

Contact: muhsinjj@gmail.com 